\title{
Using the logistic regression to predict saudi's kidney transplant rejection patients
}

\begin{abstract}
Background: Many factors may affect rejection in kidney transplant patients. Tacrolimus is immunosuppressive agent used for the prevention of the rejection in kidney patients which has narrow therapeutic range and variable pharmacokinetics. Many other factors like age, gender, Nephrotoxicity (NT), Fluid Retention (FR) may affect the rejection
\end{abstract}

Objectives: To build a predictive model based on the Binary Logistic Regression that can identify the kidney Transplant Rejection Patients that contains only the significant factors only out of all variables measured on Saudi Patients.

Method: The research population consisted of 100 SKTP at the Armed Forces Hospital in the Southern Region (AFHSR) treated with Tacrolimus and followed-up for a period of 24 months (2012 till 2014). Many other variables were measured on these patients.

Results: A significant Binary Logistic model that can be used to detect the factors affect the rejection and the probability of rejection. The significant factors (based on the stepwise logistic regression) where found to be Nephrotoxicity (NT), Fluid Retention (FR) and Tacrolimus trough level (after more than 180 days) (TTL). The Probability of rejection for the kidney can be calculated based on the equation:

$$
\text { Prob (rejection) }=\frac{1}{1+e^{-z}}
$$

where $\mathrm{z}=1.004+2.769 \times \mathrm{NT}+24.234 \times \mathrm{FR}-.856 \times \mathrm{TTL}$

Keywords: logistic regression, tacrolimus, kidney transplant, saudi
Volume 5 Issue 2 - 2017

\author{
Ezz H Abdelfattah,' Marzog S Al Nasser, ${ }^{2}$ \\ Ahmed S Ali, ${ }^{3}$ Mai A Abdul Sattar ${ }^{3}$ \\ 'Statistics Department, King Abdulaziz University, Saudi Arabia \\ ${ }^{2}$ Armed Forces Hospital, Saudi Arabia \\ ${ }^{3}$ Clinical Pharmacology Department, King Abdulaziz University, \\ Saudi Arabia
}

Correspondence: Ezz H Abdulfattah, Statistics Department, Faculty of Sciences, King Abdulaziz University, Jeddah, Saudi Arabia,Email aabelfa@kau.edu.sa

Received: December 2, 2016 | Published: February 15, 2017
Abbreviations: SKTP, saudi kidney transplant patients; AFHSR, armed forces hospital in the southern region; CYP3A, cytochrome P450 3A system; TDM, therapeutic drug monitoring; ANOVA, analysis of variance; $\mathrm{CI}$, confidence interval

\section{Introduction}

Organ transplantation requires lifelong pharmacotherapy with combination of immunosuppressant drugs which include a steroid, and immune modulator (e.g. mycophenolate mofetil, and a calcineurin inhibitor (CNI) like cyclosporine A and Tacrolimus. ${ }^{1}$

Tacrolimus became an essential component of immunosuppressant regimens in most transplant centers. Its mechanism involve selective suppression of T-lymphocyte and its pharmacokinetic is quite variable among individuals and influenced by so many variables such as race, time after transplantation, and other chronic illness. It is extensively metabolized in the liver by cytochrome P450 3A system (CYP3A), which is subject to considerable inter-individual variation and drug interaction. ${ }^{2}$ It produces many adverse reactions which include infections, malignancies, nephrotoxicity, hypertension and diabetes mellitus. ${ }^{3}$ Furthermore, Tacrolimus is liable for several drug interactions, primarily with agents affecting the cytochrome P-450 system which include food and herbal medicines. These interactions may lead to serious toxicity or rejection of the transplanted organ. ${ }^{3}$ Tacrolimus has narrow therapeutic window; under dosing is associated with an increased risk for rejection, whereas overdosing is associated with higher incidence of dose related toxicity. ${ }^{4}$

Marzouk et al. (2017) show that there is a significant relationship between Tacrolimus trough level and incidence of kidney rejection was remarkably found only after 180 days post-transplantation. During this period, Tacrolimus mean trough level $(\mathrm{ng} / \mathrm{ml})$ was $7.4 \pm 0.2$ in SKTP with no rejection, $5.3 \pm 0.7$ for those with acute rejection, and $3.8 \pm 0.4$ for those with chronic rejection. Furthermore, the coefficient of variation (CV \%) which reflects fluctuation in Tacrolimus trough level, was obviously high in SKTP with acute rejection in all postkidney-transplant periods.

The aim of present study is to build a predictive model based on the Binary Logistic Regression that can identify the kidney Transplant Rejection Patients that contains only the significant factors measured on Saudi Patients. ${ }^{5,6}$

\section{Method}

A retrospectively was done during 2012 till 2014, all adult Saudi kidney transplant patients who were followed-up in Kidney Transplant Center in Armed Forces Hospital in the Southern Region are legible for inclusion in the present study.

All adult patients of either sex, in the age group of 18-60 years, recipient of only first renal transplant and those on immunosuppressant therapy comprising of Tacrolimus, MMF and Prednisolone only were included in the study. Patients with more than one kidney transplant procedure. or who use other immune suppression regimen, or Cyclosporine based immunosuppressive therapy . Also patients who show poor drug compliance record or not attend regularly for follow up as scheduled were excluded.

At the AFHSR in Khamis Mushait (Saudi Arabia), the initial Tacrolimus orally dose taken is $0.1 \mathrm{mg} / \mathrm{kg} /$ day (two divided doses) and subsequently adjusted as guided by assessment of the patients which includes scheduled Tacrolimus trough level determination (in view of international; guidelines). the following target of Tacrolimus 
trough level were implemented in SKTP which depend on post transplantation time: $1-14$ days $(10-12 \mathrm{ng} / \mathrm{ml}), 15-28$ days $(8-10 \mathrm{ng} /$ $\mathrm{ml}), 29$ days to 180 days $(6-8 \mathrm{ng} / \mathrm{ml})$ and from 180 days onward $(5-7$ $\mathrm{ng} / \mathrm{ml})$. These reference range according to transplant protocol which approved by kidney transplant center in AFHSR .

Parameters used for measurement of outcomes in this study included: acute and chronic rejection kidney rejection as indicated by clinical manifestations (i.e. graft enlargement, fever, malaise, hypertension, oliguria and decreased renal clearance), biopsy test and histopathological findings. Furthermore, post-transplant NODM, hypertension, nephrotoxicity and neurotoxicity were recorded.

The following data were retrieved by the researcher from patients medical record (classic file and computerized system) and recoded in A data collection form which involved for example following items: Demographics: Age, height, weight and BMI. Medical profile: Source of transplanted kidney, Etiology of ESRD, type of induction therapy, current immunosuppressant medication doses, other medications, adverse effects associated with immunosuppressant therapy, incidence of rejection episodes and all relevant lab investigation including Tacrolimus blood trough level (C0), Lab test: chemistry, hematology, serology and immunology test. ${ }^{7}$

\section{Statistical analysis}

This research uses SPSS 24 software. The findings were processed through descriptive statistics (i.e. mean, SD, and coefficient of variation etc.) and inferential statistics (i.e. testing for significance, using the Chi-square test, t-test, one way Analysis of Variance (ANOVA), correlation and logistic regression). Data are expressed by means \pm SE were $\mathrm{p}$ value $<0.05$ is considered significant.

\section{Results}

Demographic characteristics and relevant clinical data are presented in Tables $1 \& 2$, to allow precise comparison with other similar studies. Out of 100 SKTP enrolled in the present study 59 were males and 41 were females, the mean age \pm SD of the patients was $37.4 \pm 14.2$ years. The median age was 34.5 years, the age ranged between 18 and 60 years, the mean $\mathrm{BMI} \pm \mathrm{SD}$ of the patients was $27.3 \pm 6.6 \mathrm{Kg} / \mathrm{m}^{2}$. The BMI ranges between 16.4 and $47.4 \mathrm{Kg} / \mathrm{m}^{2}$. The median BMI was $26.9 \mathrm{Kg} / \mathrm{m}^{2}$.

Table I Demographic data for the sample of SKTP (4I male, 59 female, total 100)

\begin{tabular}{lllll}
\hline Statistics & $\begin{array}{l}\text { Age } \\
(\text { Years })\end{array}$ & $\begin{array}{l}\text { Height } \\
(\mathbf{m})\end{array}$ & $\begin{array}{l}\text { Weight } \\
\mathbf{( K g )}\end{array}$ & $\begin{array}{l}\text { BMI } \\
\left(\mathbf{K g} / \mathbf{m}^{2}\right)\end{array}$ \\
\hline Mean \pm SD & $37.4 \pm 14.2$ & $1.58 \pm 0.08$ & $68.8 \pm 18.4$ & $27.3 \pm 6.6$ \\
\hline
\end{tabular}

Table 2 Relevant clinical variable in SKTP $(n=100)$

\begin{tabular}{lll}
\hline Parameter & Relevant Findings & $\%$ \\
\hline $\begin{array}{l}\text { Place of } \\
\text { transplantation }\end{array}$ & AFHSR (Khamis Mushate) & 81 \\
& Other places & 19 \\
Etiology of kidney & Hypertensive nephropathy & 69 \\
failure $*$ & Diabetes mellitus nephropathy & 13 \\
& Unknown & 14 \\
Induction Therapy & Yes & 7 \\
& Not reported & 89 \\
\hline
\end{tabular}

\begin{tabular}{|c|c|c|}
\hline Parameter & Relevant Findings & $\%$ \\
\hline \multirow[t]{2}{*}{$\mathrm{HBAg}$} & non-reactive & 97 \\
\hline & Reactive & 3 \\
\hline \multirow[t]{2}{*}{$\mathrm{HCV}$} & non-reactive & 96 \\
\hline & Reactive & 4 \\
\hline HIV & non-reactive & 100 \\
\hline CMV- G & Positive & 100 \\
\hline \multirow[t]{2}{*}{ CMV- M } & Negative & 100 \\
\hline & Non-relative & 23 \\
\hline \multirow[t]{2}{*}{ Type of Donor } & Relative & 59 \\
\hline & Deceased & 18 \\
\hline
\end{tabular}

Kidney Transplantation for the majority of the patients (81\%) was in AFHSR Khamis Mushait. Records showed that most of the patients (89\%) received induction therapy before transplantation. Tacrolimus initial dose was $0.1 \mathrm{mg} / \mathrm{kg} /$ day (twice daily). Limited numbers of the patients were reactive for $\mathrm{HBAg}$ and $\mathrm{HCV}$ ( $3 \%$ and $4 \%$ respectively). While all patients were negative for HIV and CMV-M; but they were positive for CMV-G.

Regarding documented etiology of ESRF; hypertension represented the major cause for kidney failure (69\%). Followed by diabetes mellitus (14\%). Glomerulonephritis among other kidney disorders were also documented as less common reasons for kidney failure.

$59 \%$ of the patients in the present study received kidney from first grade relative and $23 \%$ of them received kidney from living nonrelative donors and $18 \%$ of the transplanted kidneys were obtained from deceased persons.

Although no significant statistical relationship between the type of donor and incidence of kidney rejection in SKTP (chi-square and Fisher exact tests p-values were $>0.05$ ). The results provided an impression that SKTP received kidney from living related donor showed a relatively lower incidence of rejection episodes compared to those received cadaveric kidney.

Table 3 summarizes Tacrolimus mean trough level (ng / ml) in different post kidney transplant periods in SKTP classified according to incidence of rejection episodes.

It was noted that the significant relationship between Tacrolimus trough level $(\mathrm{ng} / \mathrm{ml})$ and incidence of kidney rejection was only established in the period after 180 days post transplantation. (P-value $=0.001$ ). In this period, Tacrolimus trough level was $7.4 \pm 0.2$ in patients who showed no rejection; $5.3 \pm 0.7$ for those who suffered acute rejection episodes and $3.8 \pm 0.4$ for those subjected to chronic rejection (Kidney loss). The $\mathrm{CV} \%$ which reflects variation between the Tacrolimus level was shown to have its greatest value in SKTP showed acute rejection in all different post kidney transplant periods.

Table 4 shows that $95 \%$ confidence interval (CI) Tacrolimus trough level for the patients who showed no rejection episodes.: from 1 - 14 days, the range was $11.5-12.7(\mathrm{ng} / \mathrm{ml})$; from $15-28$ days, it was 9.7 - $10.6(\mathrm{ng} / \mathrm{ml})$; for the 29th-180 days, it was $8.2-9.2(\mathrm{ng} / \mathrm{ml})$ and for more than 180 days, the proposed range was $6.9-7.8(\mathrm{ng})$ (Figures $1 \& 2$ ). 
Table 3 Mean Tacrolimus trough level at various time post transplantation in SKTP and its relation to incidence of rejection episodes during 24 month follow up period

\begin{tabular}{|c|c|c|c|c|c|c|c|}
\hline \multirow[t]{2}{*}{ Time Post Transplantation } & \multicolumn{2}{|c|}{$\begin{array}{l}\text { No Rejection } \\
\mathrm{N}=90\end{array}$} & \multicolumn{2}{|c|}{$\begin{array}{l}\text { Acute Rejection } \\
\mathrm{N}=8\end{array}$} & \multicolumn{2}{|c|}{$\begin{array}{l}\text { Chronic Rejection } \\
N=2\end{array}$} & \multirow[t]{2}{*}{ PValue } \\
\hline & Mean \pm SD & $\mathrm{CV} \%$ & Mean \pm SD & $\mathrm{CV} \%$ & Mean \pm SD & CV \% & \\
\hline $0-14$ days & $12.12 \pm 2.69$ & 22.2 & $|I .7| \pm 5.84$ & 49.9 & $10.50 \pm 2.33$ & 22.2 & $>0.05$ \\
\hline $15-28$ days & $10.23 \pm 2.15$ & 21.0 & $9.69 \pm 5.12$ & 52.8 & $8.65 \pm 1.77$ & 20.5 & $>0.05$ \\
\hline $29-180$ days & $8.77 \pm 2.29$ & 26.1 & $8.16 \pm 2.48$ & 30.4 & $6.65 \pm 1.34$ & 20.2 & $>0.05$ \\
\hline$>180$ days & $7.37 \pm 1.87$ & 25.4 & $5.34 \pm 2.03$ & 38.0 & $3.75 \pm 0.54$ & 14.4 & 0.001 \\
\hline
\end{tabular}

Table $495 \%$ confidence interval $(\mathrm{Cl})$ of Tacrolimus trough level $(\mathrm{TTL})(\mathrm{ng} / \mathrm{ml})$ in SKTP showed no rejection during 24 follow up period

\begin{tabular}{cccc}
\hline $\begin{array}{c}\text { Time Post } \\
\text { Transplantation }\end{array}$ & $\begin{array}{c}\text { Mean } \\
\text { Tacrolimus Trough Level }\end{array}$ & 95 \% CI Of (TTL) \\
\hline $0-14$ days & 12.12 & 11.5 & 12.7 \\
I5 - 28 days & 10.23 & 9.7 & 10.6 \\
$29-180$ days & 8.77 & 8.2 & 9.2 \\
More than I80 days & 7.37 & 6.9 & 7.8 \\
\hline
\end{tabular}

Table 5 The variables coefficients and the corresponding odds ratios

\begin{tabular}{llll}
\hline Variables Affecting Kidney Survival & Symb. & Model Coefficient & Odds Ratio \\
\hline $\begin{array}{lll}\text { Nephrotoxicity } \\
\text { Fluid Retention }\end{array}$ & NT & 2.769 & 15.949 \\
$\begin{array}{l}\text { Tacrolimus trough level (after more than } \\
\text { I80 days) }\end{array}$ & FR & 24.234 & 33462461965.163 \\
$\begin{array}{l}\text { Constant } \\
\text { TTL }\end{array}$ & Constant & -.856 & .425 \\
\hline
\end{tabular}

\section{Logistic regression}

When the dependent variable is binary or has only two values (yes, no), the regression method is known as binary logistic regression. Before this, a method of discreminatnt analysis was also in practic but this allows direct prediction of group membership but the assumptions of multivariate normality if independent variables is required for prediction rule to be optimal. Logistic regression model requires fewer assumptions than discriminant analysis and even when the assumptions required for discriminant analysis are not met, logistic regression, still performs well. In logistic regression one can directly estimate the probability of an event where as in linear regression it is not possible as they do not fall in the interval 0 to 1 .

The method of logistic regression has become the standard method of analysis for the last three decades, when the dependent variable is binary or dichotomous (yes, no). The difference between logistic and linear regression lies both in the choice of a model and assumptions. Once the difference is accounted for, then logistic method of analysis follows the same general principles as used in linear regression. Stepwise regression is a method of fitting regression models in which the choice of predictive variables is carried out by including only significant variables to the rmodel in many steps based on the number of variables to be including to the model. In each step, a variable is considered for addition to or subtraction from the set of explanatory variables.

We applied the binary logistic regression by considering having a kidney rejection as a depaendent variable and all other variables are considered as independent variables. A significant Binary Logistic model can be used to detect the factors affect the rejection and the probability of rejection. The significant factors (based on the stepwise logistic regression) where found to be Nephrotoxicity (NT), Fluid Retention (FR) and Tacrolimus trough level (after more than 180 days) (TTL). The Probability of rejection for the kidney can be calculated based on the equation [8-28]:

$$
\text { Prob (rejection) }=\frac{1}{1+e^{-z}}
$$

where $\mathrm{z}=1.004+2.769 \times \mathrm{NT}+24.234 \times \mathrm{FR}-.856 \times \mathrm{TTL}$

The following table summarize the variables coefficients and the corresponding odds ratios (Table 5): 


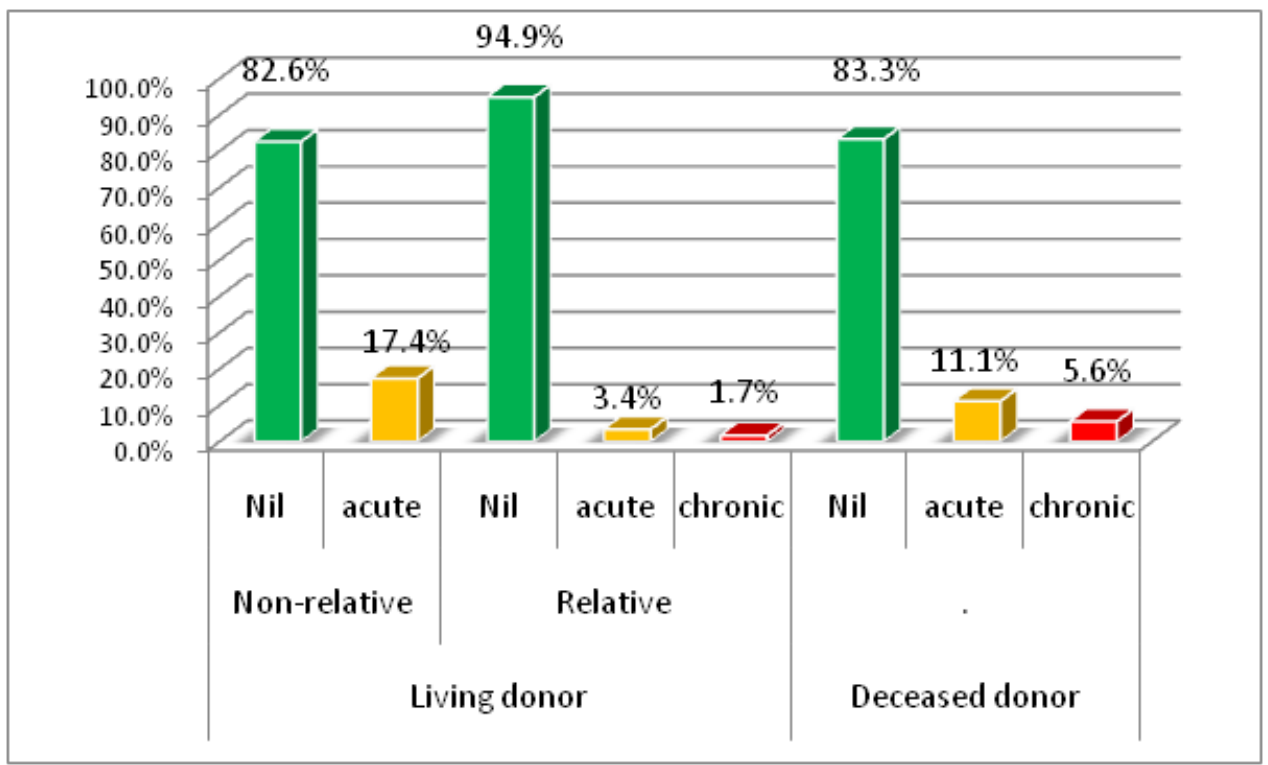

Figure I Correlation between type of donor and incidence of renal rejection in SKTP.

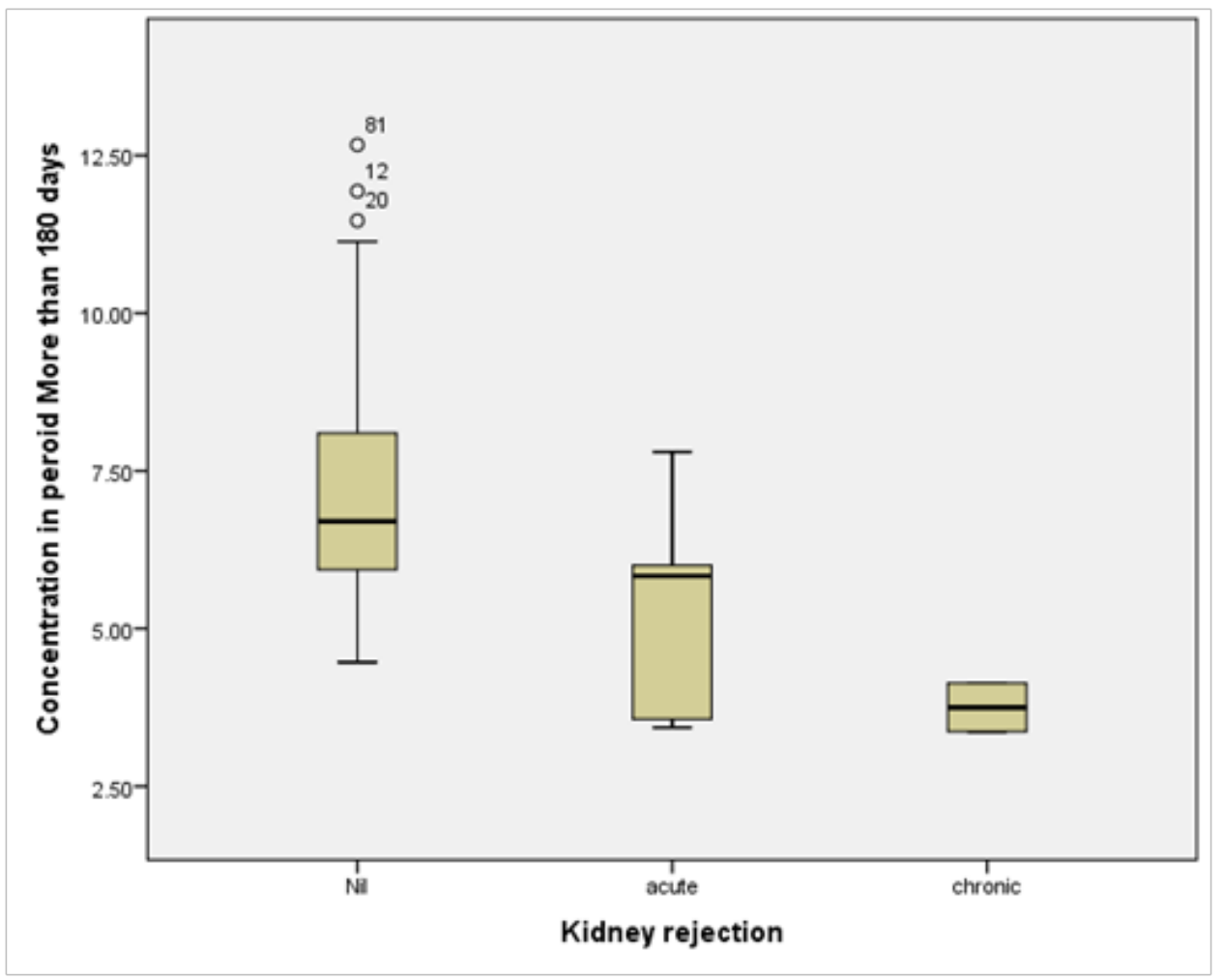

Figure 2 Box plot for median Tacrolimus trough level ( $\mathrm{ng} / \mathrm{ml}$ in the period 6-24 month after transplantation.

\section{Interpretation of odds ratio}

A value of 15.9 of odds ratio for Nephrotoxicity means that with the existence of Nephrotoxicity, there is a chance about 16 times for the kidney rejection in compare of non existence provided all other factors are kept constant.

Also A value of 33.46E9 of odds ratio for Fluid Retention means that with the existence of Fluid Retention, there is a confirmed kidney rejection in compare of non existence provided all other factors are kept constant.

With the increase of one $\mathrm{ng} / \mathrm{ml}$ in Tacrolimus trough level (after more than 180 days) the risk of rejection is decreased 0.425 times provided all other factors are kept constant.

As an example on how to use the logistic regression equation for prediction, suppose that a patient has the following measurements: 
$\mathrm{NT}=$ yes, $\mathrm{FR}=\mathrm{No}$ and $\mathrm{TTL}=3$, Then

$z=1.004+2.769 \times 1+24.234 \times 0-.856 \times 3=1.205$

Hence, the probability of rejection:

$$
\operatorname{Prob}(\text { rejection })=\frac{1}{1+e^{-1.205}}=0.77
$$

Examples for different possibilities

\begin{tabular}{llll}
\hline Nephrotoxicity & F.R. & Conc. & Probability of Rejection \\
\hline Yes & Yes & 3 & $\mathrm{I}$ \\
Yes & Yes & 8 & $\mathrm{I}$ \\
Yes & No & 3 & 0.77 \\
Yes & No & 8 & 0.04 \\
No & Yes & 3 & $\mathrm{I}$ \\
No & Yes & 8 & $\mathrm{I}$ \\
No & No & 3 & 0.17 \\
No & No & 8 & 0.00 \\
\hline
\end{tabular}

\section{Conclusion}

Trough level monitoring during the 1 st 6 month post transplantation and achievement of target level couldn't solely exclude the risk of incidence of rejection. After a period of 180 days post-transplantation, inadequate Tacrolimus trough level $(<5 \mathrm{ng} / \mathrm{ml}$ can lead to chronic rejection (graft loss). Fluctuation in Tacrolimus trough is a major risk factor in incidence of rejection. Monitoring trough level is a valuable tool to adjust the Tacrolimus after 6 month post transplantation and its recommended to keep within 5-8 ug/ ml. Further studies are recommended to evaluate the utility of the LSS for TDM of Tacrolimus in SKTP first 6 months post transplantation. The significant factors (based on the stepwise logistic regression) where found to be Nephrotoxicity (NT), Fluid Retention (FR) and Tacrolimus trough level (after more than 180 days) (TTL).

\section{Acknowledgement}

None.

\section{Conflict of interest}

None.

\section{References}

1. Krensky AM, Vincenti F, WM B. Immunosuppressants, Tolerogens, and Immunostimulants. In: Brunton LL LJ \& Parker KL, editors. Goodman and Gillman's The Pharmacological basis of therapeutics. USA, New York: McGraw Hill. 2011;1405-1431.

2. Taylor AL, Watson CJ, Bradley JA. Immunosuppressive agents in solid organ transplantation: Mechanisms of action and therapeutic efficacy. Crit Rev Oncol Hematol. 2005;56(1):23-46.

3. Katabathina V, Menias CO, Pickhardt $\mathrm{P}$, et al. Complications of Immunosuppressive Therapy in Solid Organ Transplantation. Radiol Clin North Am. 2015;54(2):303-319.
4. Sweetman S. Martindale: the complete drug reference. London: Pharmaceutical Press; 2014

5. De Jonge H, Naesens M, Kuypers. New insights into the pharmacokinetics and pharmacodynamics of the calcineurin inhibitors and mycophenolic acid: possible consequences for therapeutic drug monitoring in solid organ transplantation. Ther Drug Monit. 2009;31(4):416-435.

6. Mohammad pour N, Elyasi S, Vahdati N, et al. A review on therapeutic drug monitoring of immunosuppressant drugs. Iran J Basic Med Sci. 2011;14(6):485-498.

7. Wallemacq P, Goffinet JS, O'Morchoe S, et al. Multi-site analytical evaluation of the Abbott ARCHITECT tacrolimus assay. Ther Drug Monit. 2009;31(2):198-204.

8. Khan S, Hussain T, Azam H, et al. Statistical study of risk factors of End Stage Renal Failure in Peshawar, Pakistan. Open Access Maced J Med Sci. 2015;3(1):189-191

9. El Minshawy O1, Ghabrah T, El Bassuoni E. Diabetic nephropathy as a cause of end-stage renal disease in Tabuk area, Saudi Arabia: a four-year study. Saudi J Kidney Dis Transpl. 2014;25(5):1105-1109.

10. Al-Sayyari AA, Shaheen FA. End stage chronic kidney disease in Saudi Arabia. A rapidly changing scene. Saudi Med J. .2011;32(4): 339-346.

11. Hassanien AA, Al-Shaikh F, Vamos EP, et al. Epidemiology of endstage renal disease in the countries of the Gulf Cooperation Council: a systematic review. JRSM Short Rep. 2012;3(6):38.

12. Al Suleiman MH, Kfoury HK, Jondeby MS, et al. Progression of diabetic nephropathy in Saudi patients with type 2 diabetes mellitus. Endocrinologist. 2008;18(5):230-232.

13. Halimi JM. Low-grade proteinuria and microalbuminuria in renal transplantation. Transplantation. 2013;96(2):121-130.

14. Rodrigo E, Segundo DS, Fernández-Fresnedo G, et al. Within-Patient Variability in Tacrolimus Blood Levels Predicts Kidney Graft Loss and Donor-Specific Antibody Development. Transplantation. 2015;100(11): 2479-2485.

15. Shiohira $\mathrm{H}$, Yamada $\mathrm{S}$, Uehara $\mathrm{H}$, et al. Increased plasma tacrolimus concentration after single intravenous administration of voriconazole: a case of drug-drug interaction. Ryukyu Med J. 2014;33(1-3):41-44.

16. Gaynor JJ, Ciancio G, Guerra G, et al. Lower tacrolimus trough levels are associated with subsequently higher acute rejection risk during the first 12 months after kidney transplantation. Transpl Int. 2015;29(2):216-226.

17. Mathew BS, Fleming DH, Jeyaseelan V, et al. A limited sampling strategy for tacrolimus in renal transplant patients. Br J Clin Pharmacol. 2008;66(4):467-472.

18. Van Boekel GA, Donders AR, Hoogtanders KE, et al. Limited sampling strategy for prolonged-release tacrolimus in renal transplant patients by use of the dried blood spot technique. Eur J Clin Pharmacol. 2015;71(7): 811-816.

19. Jusko WJ, Thomson AW, Fung J, et al. Consensus document: therapeutic monitoring of tacrolimus (FK-506). Ther Drug Monit. 1995;17(6):606614.

20. Gaston RS. Maintenance immunosuppression in the renal transplant recipient: an overview. Am J Kidney Dis. 2001;38(6):S25-S35.

21. Hardinger K, Brennan DC. Maintenance immunosuppressive therapy in renal transplantation in adults. 2016.

22. Lam S, Partovi N, Ting LS, et al. Corticosteroid interactions with cyclosporine, tacrolimus, mycophenolate, and sirolimus: fact or fiction? Ann Pharmacother. 2008;42(7):1037-1047. 
23. Venkataramanan R, Swaminathan A, Prasad $\mathrm{T}$, et al. Clinical pharmacokinetics of tacrolimus. Clin Pharmacokinet. 1995;29(6):404430 .

24. Cheng Y, Li H, Meng Y, et al. Effect of CYP3A5 polymorphism on the pharmacokinetics of tacrolimus and acute rejection in renal transplant recipients: experience at a single centre. International journal of clinical practice. 2015;69(S183):16-22.

25. Yang TH, Chen YK, Xue F, et al. Influence of CYP3A5 genotypes on tacrolimus dose requirement: age and its pharmacological interaction with ABCB1 genetics in the Chinese paediatric liver transplantation. Int J Clin Pract Suppl. 2015 ;(S183):53-62.
26. Fathy M, Kamal M, Mohy A, et al. Impact of CYP3A5 and MDR-1 gene polymorphisms on the dose and level of tacrolimus among livingdonor liver transplanted patients: single center experience. Biomarkers. 2016;21(4):335-341.

27. Rančić N, Dragojević-Simić V, Vavić N, et al. Tacrolimus concentration/ dose ratio as a therapeutic drug monitoring strategy: the influence of gender and comedication. Vojnosanit Pregl. 2015;72(9):813-822.

28. Al-Nasser MS, Ali AS, Abdul Sattar MA, et al. Therapeutic Drug Monitoring of Tacrolimus in Saudi Kidney Transplant Patients. J Nephrol Ther. 2016;1:5. 